\title{
Investigation of the Influence of Cold-Treatment on Properties of Advanced High Strength Automotive Steels
}

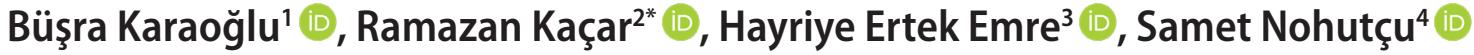 \\ ${ }^{1}$ Graduate School of Natural and Applied Science/Karabuk University /Turkey \\ ${ }^{2-4}$ Karabuk University/Manufacturing Engineering Department/Turkey
}

\begin{abstract}
Due to the moderate formability of high strength low alloy steels (HSLA), the steels called transformation induced plasticity (TRIP) have been developed. They are especially used in the production of automobile shock absorbers and the beam supporting parts. The microstructure of these steels consists of the distribution of ferrite, bainite and $(5-10 \%)$ residual austenite phases. The strength and formability of steels are generally provided by bainite, ferrite and the residual austenite phases in the structure. During shaping, the residual austenite turns into martensite and gives high strength to the steel. Considering the literature studies, it is pointed out that there is a lack of information about the effect of cold treatment on TRIP steels. For this reason, in the study, cold treatment performed to the TRIP800 steel for two hours at various temperatures. Thus, the mechanical properties and microstructure of the samples were examined in detail.
\end{abstract}

Key words: TRIP steels, Cold treatment, Mechanical properties, Microstructure

\section{INTORDUCTION}

The formability of commercial low ductility high strength steels decreases almost linearly due to the increased strength. However, advanced high strength steels are characterized by their combination of strength and formability. Due to their sought and desired properties, these steels to be use in a wide range of industries [1,2]. One of the advanced high strength steel varieties developed for industrial applications and especially for automotive production is TRIP steels, which means plasticity caused by transformation [3-5]. Much research and improvements are being conducted in the automobile industry to improve their safety and fuel consumption performance [6,7]. As a result of these researches and developments, it is important that cars are designed and manufactured to be durable and safe when exposed to static, impact and variable loads [8-10]. TRIP steels are used in a wide range in the production of shock absorber and beam supporting parts of automobiles due to their high strength and formability [11]. De Cooman [12], reported that two types of high strength steels $(<1000 \mathrm{MPa}$ and $>1200 \mathrm{MPa})$ are needed for safety-based car body design. These are dual-phase (DP) and TRIP steels with a high energy absorption potential tensile strength below $1000 \mathrm{MPa}$, for dynamic loading occurring during car crashes or collisions [12,13]. When it comes to protecting vehicle passengers, the type of sheet material used as a load transfer barrier is specified as martensitic steels with a tensile strength over $1200 \mathrm{MPa}$ $[12,13]$. In summary, these advanced high strength steels are preferred and used for applications where high strength and ductility as well as excellent formability and weight savings are required $[14,15]$.

In recent years, the effects of low-temperature processes on the properties of materials are remarkable. Low-temperature processes are called cold process (cold heat treatment or cold treatment) up to $-80{ }^{\circ} \mathrm{C}$ (processes in dry ice), and those performed at liquid nitrogen temperature are called deep cryogenic processes. As stated in the study "Microstructure of cryogenically treated M2 tool steels" conducted by Huang et.al.[16]; many researchers point out that the cryogenic process increases the wear resistance of steels by providing the complete transformation of residual austenite to martensite. Another group of researcher claims that the cryogenic process improves the wear resistance by facilitating the formation of $\eta$-type carbides in martensite $[17,18]$. It is known that applications at low temperatures (cryogenic temperatures) significantly affect the mechanical properties of austenitic stainless steels by martensitic transformation. Powell et al. [19] and Hecker et al. [20] investigated the effects of strain rate and stress condition on strain-based martensite formation and mechanical properties on austenitic stainless steel. The effect of temperature and strain on the martensi-
* Corresponding author

Email: rkacar@karabuk.edu.tr
European Mechanical Science (2021), 5(3): 183-188

doi: https://doi.org/10.26701/ems.830012

Received: November 23, 2020

Accepted: February 23, 2021 
tic transformation was indicated by Powell [19] while, the martensite ratio under multiaxial loading was determined by Hecker et.al. [20] Yoo et al. [21], investigated the dynamic loading structural analysis of advanced high strength materials performed at low temperatures and simulated the temperature and strain rate change of TRIP steels in low temperature applications. They pointed out that advanced high strength materials also show extreme sensitivity depending on the stress rate and temperature [21]. Additionally, the experimental results simulated with the proposed numerical model revealed that TRIP steels exhibit nonlinear material properties at low temperature [21].

Literature research points out to a lack of knowledge about the effect of low service temperatures on the properties of TRIP steels. For this reason, in the study; TRIP800 steels were cold heat treated at various temperatures for two hours. Then, microstructure and mechanical properties of samples were examined in detail after bringing them to room temperature.

\section{MATERIAL AND METHOD}

\subsection{Material:}

The chemical content (\% weight) of TRIP800 steel, which is commercially supplied in $1000 \times 1500 \times 1.5$ mm dimensions, is given in Table 1.

Table 1. Chemical composition of TRIP800 grade steel

\begin{tabular}{|c|c|c|c|c|c|c|c|c|c|}
\hline $\begin{array}{c}\text { Element } \\
\text { (\% weight) }\end{array}$ & C & Si & Mn & P & S & Cr & Mo & Al & Fe \\
\hline TRIP800 & 0,22 & 1,576 & 1,619 & 0,013 & 0,003 & 0,016 & 0,014 & 0,036 & Remain \\
\hline
\end{tabular}

\subsection{2 Preparation of Experimental Test Samples:}

The tensile test specimens in accordance with the TS EN ISO 6892-1 standard were obtained by using the press cutting die for determining mechanical properties.

In order to assess effect of the cold treatment on mechanical properties of TRIP800 steel, the test samples were kept in groups of different temperatures at $0{ }^{\circ} \mathrm{C},-20{ }^{\circ} \mathrm{C}$ and -50 ${ }^{\circ} \mathrm{C}$ for two hours, respectively. The tensile tests were applied after the samples were brought to room temperature in open atmosphere conditions. A group of samples were also tested at room temperature $\left(25^{\circ} \mathrm{C}\right)$ without any cold treatment for comparison. Tensile tests were carried out in a device of SHIMAZDU with a capacity of $50 \mathrm{kN}$ at a strain rate of $2 \mathrm{~mm} / \mathrm{min}$. To minimize the experimental errors, a set of three tensile test samples were tested for each condition. In addition, hardness measurement was carried out by applying a load of $500 \mathrm{~g}$ in the Vickers microhardness tester.

Metallography samples were molded with cold resin and then prepared by using classical metallography methods for structural evaluation. The samples were etched with $2 \%$ nitric acid solution. Carl Zeiss Ultra Plus Fe-SEMs brand scanning electron microscope (SEM) and EDS analysis system were used to examine the microstructure and fracture surfaces.

\section{RESULTS AND DISCUSSION}

\subsection{Tensile Tests:}

The mean yield and tensile strength, elongation amount and breaking point are given in Table 2 for TRIP800 steel, which is cold processed for two hours at various temperatures. The mean stress-strain curves are shown in Figure 1.

Table 2. Mechanical properties of TRIP800 steel cold heat treated at various temperatures.
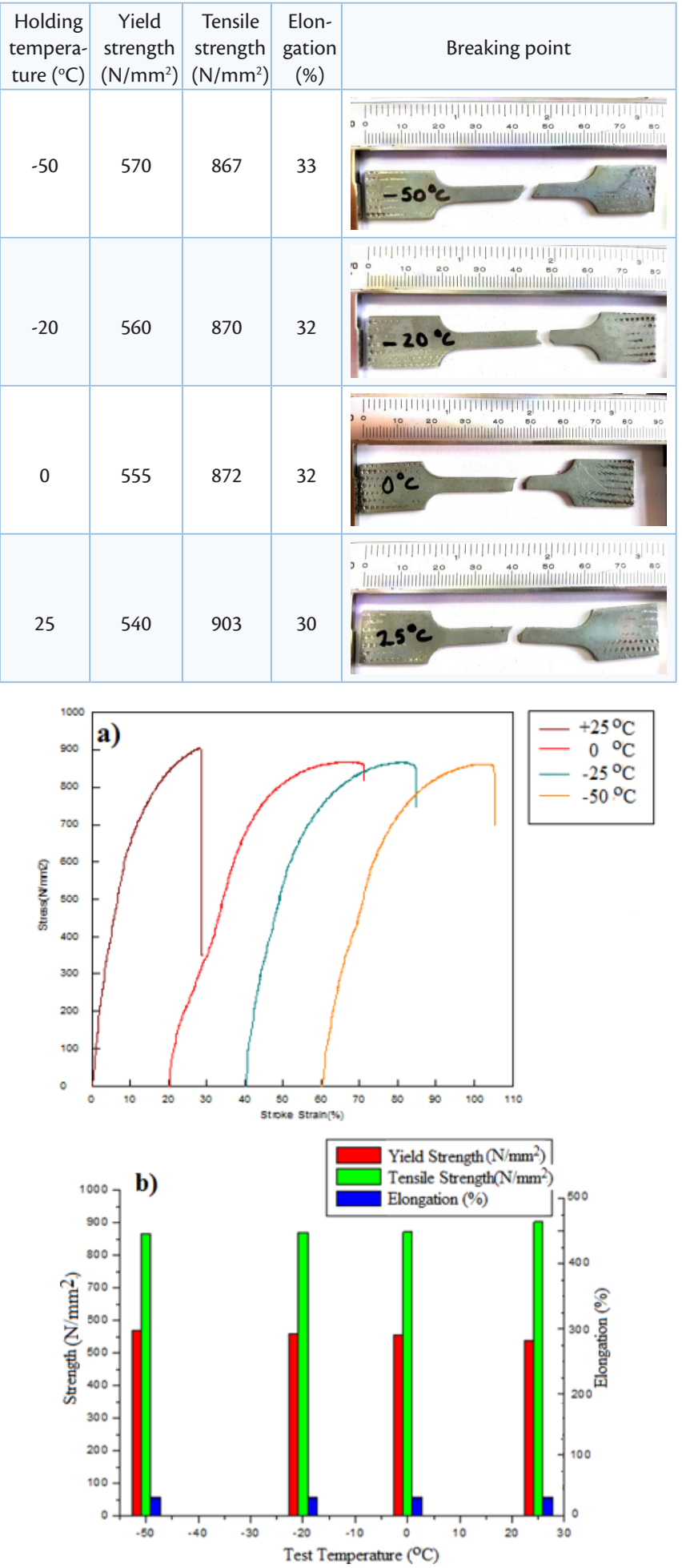

Figure 1. Cold heat treatment of TRIP800 steel at various temperatures; a) stress-strain curves, b) The graphical representation of yield, tensile strength, and elongation versus cold treatment temperature.

As seen from Table 2 and Figure 1; the mechanical proper- 
ties of TRIP800 steel, the yield strength, tensile strength and elongation of the TRIP800 steel were determined. It has been found that cold treatment has no significant effect on the tensile strength and formability of TRIP800 steel. However, the cold treatment causes an increase in the yield strength of the steel depending on decreasing the temperature. It was determined that the yield strength of TRIP800 steel was $540 \mathrm{~N} / \mathrm{mm}^{2}$ at room temperature and increased to $570 \mathrm{~N} /$ $\mathrm{mm}^{2}$ in the sample that was cold processed at $-50{ }^{\circ} \mathrm{C}$. The yield strength of steels is significantly affected by temperature [22]. In this study, the yield strength of TRIP800 steel samples increased approximately $30 \mathrm{~N} / \mathrm{mm}^{2}$ with the decreasing cold treatment temperature.

The relationship between yield strength and cold treatment temperature can be explained by the change in a volumetric ratio of phases in the microstructure of TRIP steel. The general structure of TRIP steel has the majority of ferrite and bainite phases (about 85\%) and the minority of the residual austenite phase (about 15\%) as well as martensite transformed by residual austenite. Increasing on the yield strength of the TRIP800 steel by decreasing cold treatment temperature can attribute to strain induced martensitic transformation and the dominant role of ferrite and bainite phases in the structure. In a study, Wang et al. [23] investigated the relationship between yield and tensile strength and temperature of TRIP steel at temperatures between $20{ }^{\circ} \mathrm{C}$ and $-40{ }^{\circ} \mathrm{C}$. It has been reported that the yield strength of steel increases with decreasing temperature down to $-5{ }^{\circ} \mathrm{C}$, then decreases down to $-20^{\circ} \mathrm{C}$, and increases again as it goes down to temperatures lower than $-20^{\circ} \mathrm{C}$. This anomalous event at -5 ${ }^{\circ} \mathrm{C}$ is explained as the transition point from stress-induced martensitic transformation to strain-induced martensitic
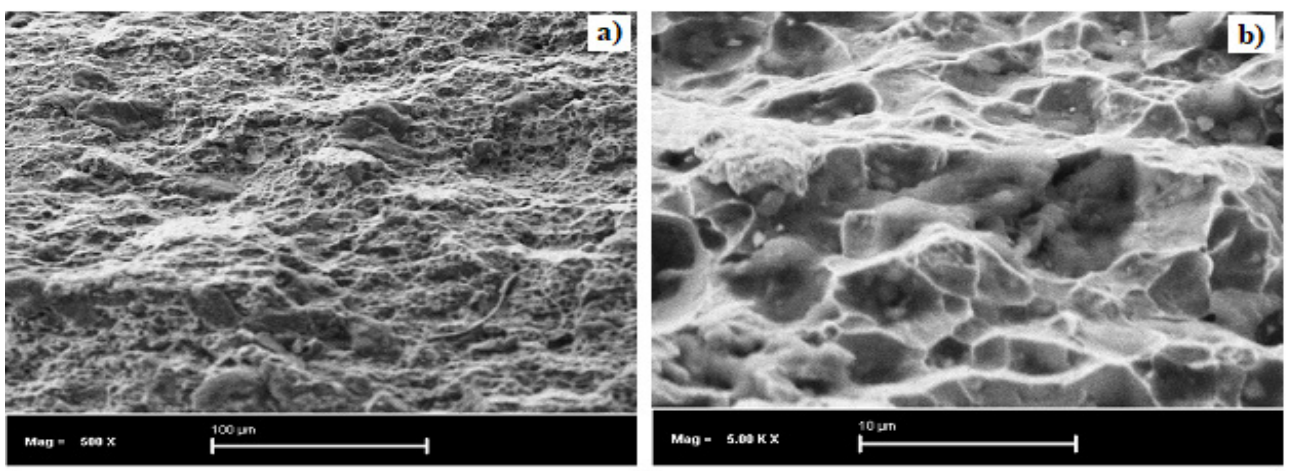

Figure 2. Fracture surface image of TRIP800 steel tested at $25^{\circ} \mathrm{C}$ a) lower magnification b) higher magnification
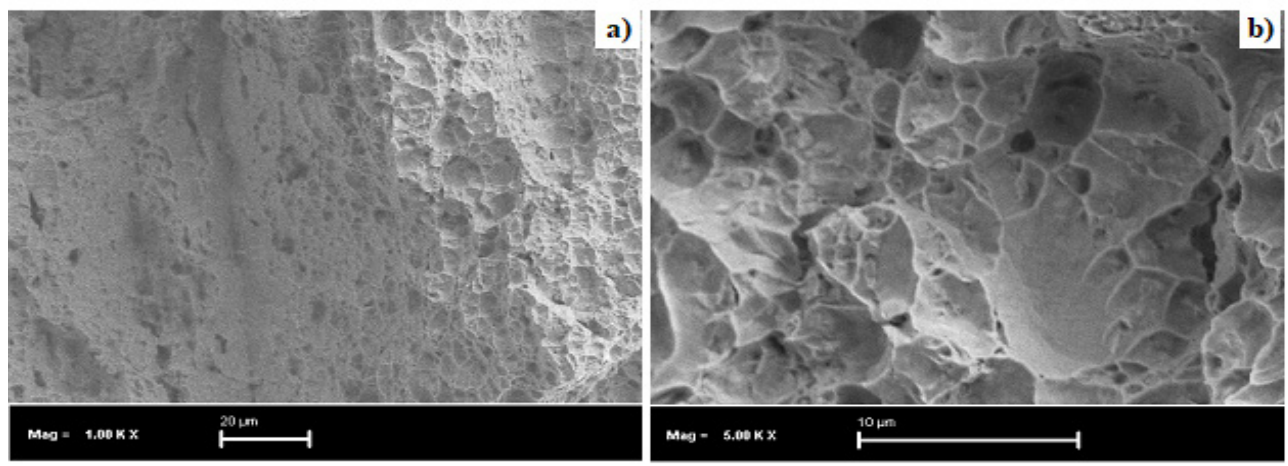

Figure 3. Fracture surface image of TRIP800 steel cold-treated at $-50{ }^{\circ} \mathrm{C}$ a) lower magnification b) higher magnification 
particles, which are thought to be metal carbides inside the dimples, are responsible for the onset of fracture has been tried to be determined. For this purpose, point EDS analysis were taken from the fracture surfaces of the sample tested at room temperature and the result is shared in Figure 4.
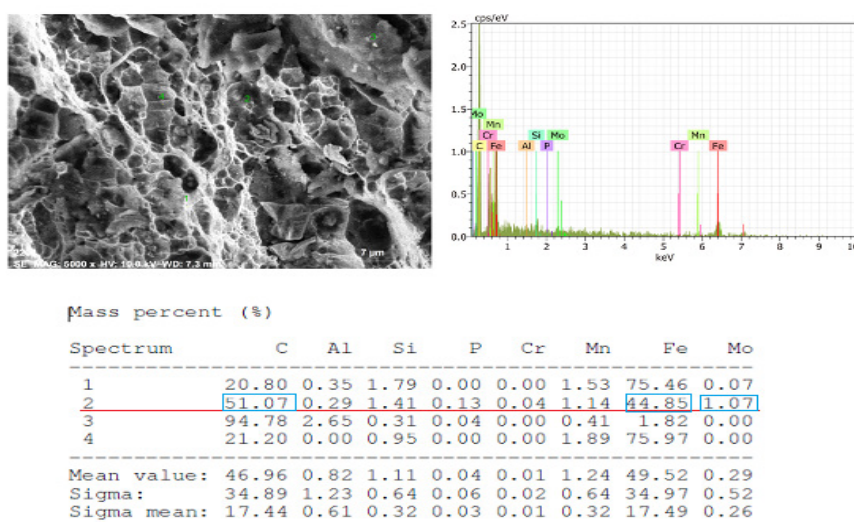

Figure 4. EDS analysis result of TRIP800 steel fracture surface tested at 25 ${ }^{\circ} \mathrm{C}$

As seen from Figure 4, the higher amount of Fe, Mo and C elements presence in EDS analysis results indicate the possibility of carbide formation in TRIP 800 steels. As a result of analysis, (Fe and Mo) C carbide formations in TRIP800 steel form the precursor for the initiation of fracture. It is reported that $\mathrm{Fe}_{4} \mathrm{M}_{2}(\mathrm{M}=\mathrm{W}, \mathrm{Mo}, \mathrm{Cr}, \mathrm{V}) \mathrm{C}$ carbide formations occur in steels with or without cryogenic treatment [16].

\subsection{Hardness Measurement:}

In the study, the results of hardness measurement performed on samples that were cold treated for two hours at various temperatures are graphically shown in Figure 5.

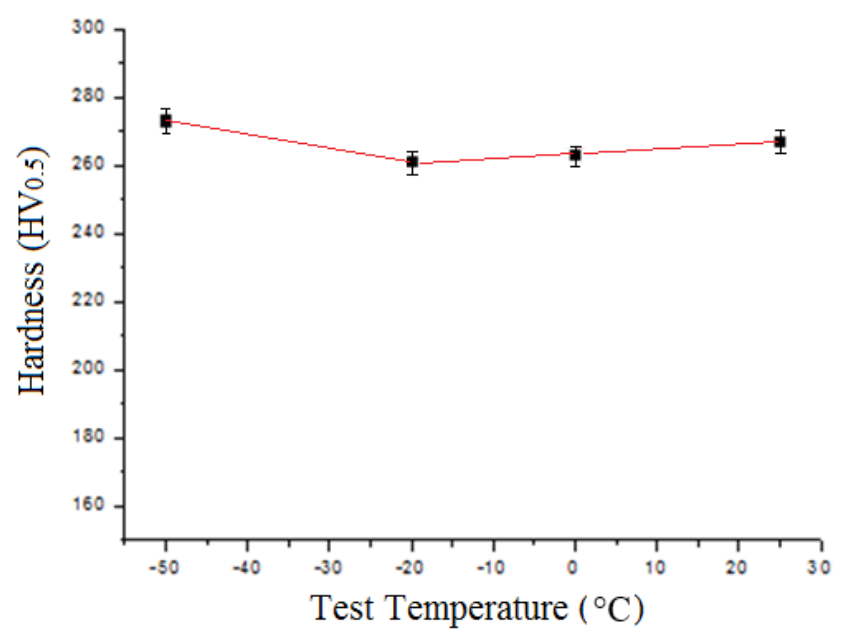

Figure 5. Hardness profile of TRIP800 steel cold treated at various temperatures.

As seen in Figure 5; the hardness of TRIP800 steel which is consisting of bainite and residual austenite phases in a ferrite matrix was measured in the range of $261 \pm 2-273 \pm 2$ $\mathrm{HV}_{0.5}$ on average. The lowest hardness was measured in the cold treated sample at the temperature of $-20{ }^{\circ} \mathrm{C}$ while, the highest hardness was measured in the cold treated sample at the temperature of $-50{ }^{\circ} \mathrm{C}$. The close results indicate that the hardness of TRIP800 steel is not significantly affected by cold treatment. As mentioned earlier, residual stress that occur in the ferrite and bainite phases arising from the production process in TRIP800 steel may be responsible for the slight change in hardness at cold treatment temperatures.

\subsection{Microstructure Evaluation:}

The microstructure images of TRIP800 steel, which was cold heat treated for two hours at various temperatures, are shown in Figure 6.

Its microstructure consists of bainite and residual austenite phases dispersed in the ferrite matrix. Responsible for the higher strength, formability, and uniform elongation of TRIP800 steel are the bainite, ferrite phases and martensite phase formed by the transformation of the residual austenite, respectively.

As seen from Figure 6d; because of cold treatment at $-50^{\circ} \mathrm{C}$, no significant structural change was detected in the microstructure of TRIP800 steel. However, the following situation should not be ignored. The structural transformation of steels with martensite transformation finishing temperature below room temperature is completed, especially with the increase in martensite volume ratio. For this reason, it is thought that the decrease in the volume ratio of residual austenite phases in the ferrite matrix in the structure of steel is replaced by an increase in the amount of martensite.

In recent years, it has been stated that cryogenic heat treatment application suppresses dynamic recovery in aluminum alloys and increases dislocation density, which are responsible for development of ultra-fine grain structure in the material thus increases the strength [25]. However, considering the cold treatment temperature and application time applied to TRIP800 steel in this study, ultra-fine grains formation cannot be expected in the structure. In addition, the slight change in TRIP800 steel hardness at the specified temperatures may be related to factors such as loosening of residual stresses, coarsening of martensite, reduction of dislocation density, segregation of carbon and alloying element atoms and carbide precipitate formation.

There is uncertainty as to how cold treatment affects carbide formation in martensite. However, it is stated by Huang et al. [16] that two issues come to the fore in this regard. In the first one, lowering the $\mathrm{M}_{\mathrm{S}}$ initial temperature for the transformation from austenite to martensite, and the second, waiting for sufficient time at this temperature are specified as requirements for high carbide formation. Crystal discontinuity such as dislocation and twinning cause microscopic residual stresses during cooling. These stresses cause changes in microstructure. It is stated that this leads to different thermal shrinkage and the transformation of residual austenite to martensite [16]. The martensite must be cooled below a certain temperature to create residual stress and sufficient crystalline defects. It is stated that the long holding time at the specified temperature may cause local diffusion process, causing the carbon and alloy atoms to cluster and 


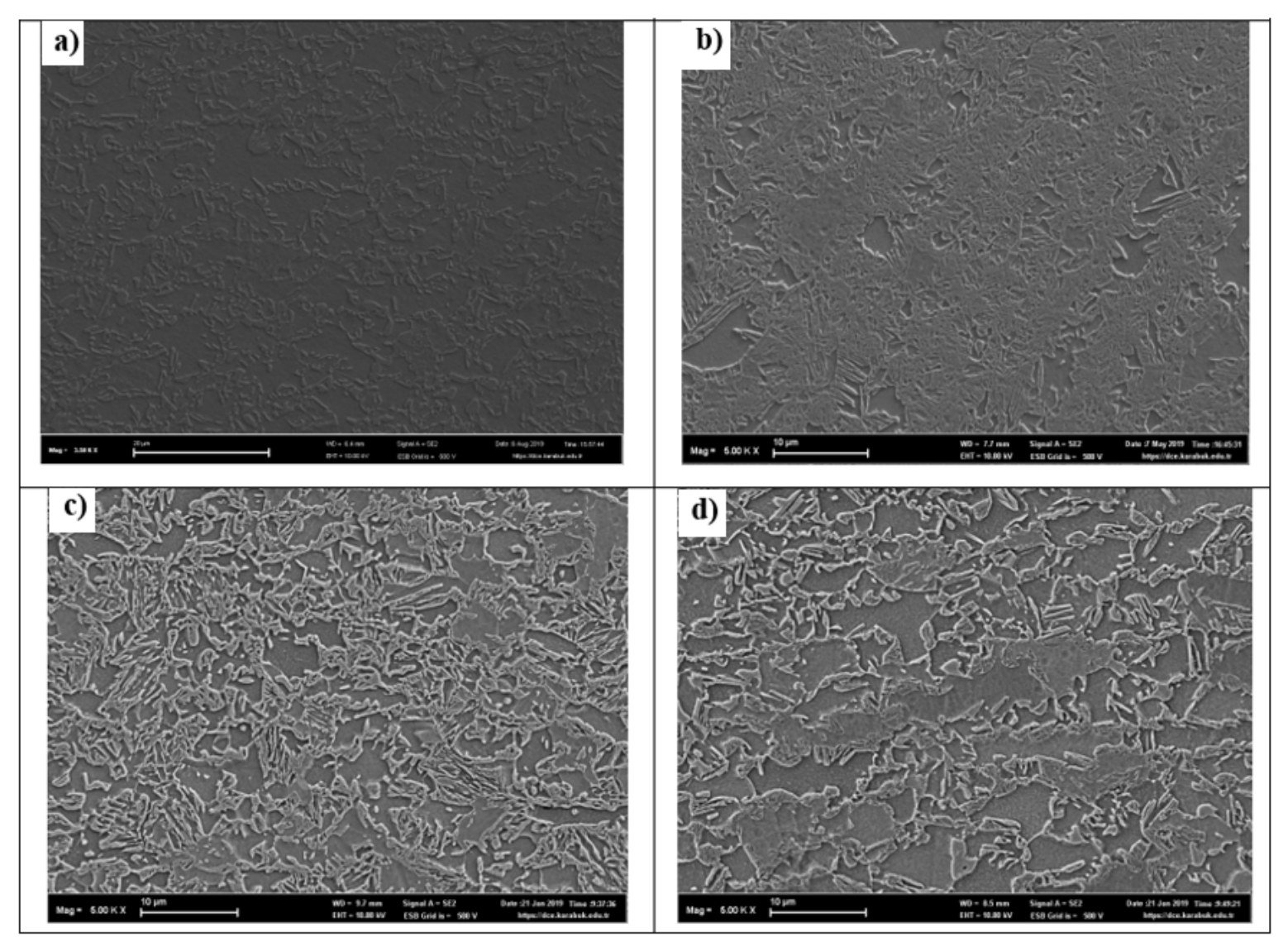

Figure 6. Microstructure of cold heat treated TRIP800 steel at different temperatures a) $\left.+25^{\circ} \mathrm{C}, \mathrm{b}\right) 0^{\circ} \mathrm{C}$, c) $\left.-20^{\circ} \mathrm{C}, \mathrm{d}\right)-50^{\circ} \mathrm{C}$.

cause crystal defects. With decreasing temperature, martensite reaches oversaturation, causing increased distortion and thermodynamic instability in the crystal lattice [16]. These two conditions cause the segregation of carbon and alloy atoms as well as defects. This aggregation of carbon and alloy atoms enables carbide nucleation and growth during the subsequent reheating or tempering process to room temperature [16].

The crystal defects density in the structure consisting of martensite is also very high. It is very difficult to observe in practice the segregation of carbon and alloy atoms as well as defects during the cryogenic process. However, neutron diffraction analysis in Huang's study indicates that the lattice parameters "a" and "c" differ during the cooling and reheating of the martensite phase [16]. The lattice parameter "a" varies almost linearly with temperature. The same graphic formation during heating and cooling indicates pure thermal elastic effect. However, the lattice parameter "c" decreases first during cooling, but it increases very slowly while warming [16]. This situation leads to the conclusion that carbon atom segregation is in the cold treatment. The carbon atom is generally in octahedral or tetrahedral places in the martensite phase. It has been reported that the segregation of carbon atoms from octahedral or tetrahedral locations to places with crystal defects mainly affects the "c" lattice parameter [16].

It is thought that the two hours cold treatment at the temperatures of $-20{ }^{\circ} \mathrm{C}$ and $-50{ }^{\circ} \mathrm{C}$ can cause clustering and segregation of carbon and alloy atoms in TRIP800 steel, which contains enough residual stress due to the production process. In addition, it is believed that cold treatment causes more crystal defects such as dislocation and twinning. It is thought that the carbides that will form when the TRIP800 steel is warming up to room temperature after the cold treatment applied, reduce the amount of carbon and alloying elements in the matrix and causes a slight change in hardness because of stress relief.

\section{CONCLUSION}

The effects of cold heat treatment applied at various temperatures on the properties of TRIP800 steels were investigated. The findings obtained from the samples tested at ambient temperature after cold treatment can be summarized as follows.

- It was determined that the decreasing cold treatment temperature of TRIP800 steel did not create a significant change in tensile strength and ductility but its increased yield strength.

- The fracture surfaces examination of the tensile test specimens indicates semi ductile-semi brittle fracture behaviour. The formations of secondary phase particles, which are metal carbides, inside the dimples are thought to be responsible for the onset of fracture.

- The hardness of TRIP800 steel, which consists of bainite and residual austenite phases in a ferrite matrix, was measured in the range of 261-273 HV0.5. The lowest 
hardness was found in the sample cold treatment at $-20{ }^{\circ} \mathrm{C}$, the highest hardness was measured in the cold treated sample at $-50{ }^{\circ} \mathrm{C}$. The residual stress may be responsible for the slight change in hardness. It is believed that the carbides that form when the TRIP800 steel is warming up to room temperature after the cold treatment applied, reduce the amount of carbon and alloying elements in the matrix thus causes a slight change in hardness as a result of stress relief.

- TRIP800 steel consists of bainite and residual austenite phases dispersed in ferrite matrix. Because of cold treatment up to $-50^{\circ} \mathrm{C}$, no significant microstructural change was detected in the microstructure of TRIP800 steel. However, it is thought that the decrease in the volume ratio of residual austenite phases in the ferrite matrix in the structure of steel is replaced by an increase in the amount of martensite.

\section{ACKNOWLEDGEMENTS}

This study was supported by the Scientific Research Projects Unit of Karabük University with the project code number FYL-2019-2021. We would like to thank for their support.

\section{REFERENCES}

[1] Chiyatan T., Uthaisangsuk V. (2020). Mechanical and fracture behavior of high strength steels under high strain rate deformation: Experiments and modelling Materials Science and Engineering A, 779, 27, 139125, DOl: 10.1016/j.msea.2020.139125.

[2] Spena PR, Cortese L., Nalli F., Májlinger K. (2019). Local formability and strength of TWIP-TRIP weldments for stamping tailor welded blanks (TWBs). The International Journal of Advanced Manufacturing Technology,101, 757-771, DOI:10.1007/s00170-018-2946-1.

[3] Krizan D. (2006). TRIP Steels: Advanced high strength multiphase steels for automotive applications. 14th International Scientific Conference CO-MAT-TECH, Trnava, Slovak Republic.

[4] Kapustka, N., Conrardy, C., Babu, S., Albright, C. (2008). Effect of GMAW process and material conditions on DP 780 and TRIP 780 welds. Welding Journal, 87(6):135-148.

[5] Yinghui, Z., Yonli, M., Yonglin, K., Hao Y. (2006). Mechanical properties and microstructure of TRIP steels produced using TSCR process. Journal of University of Science and Technology, 13(5):416421, DOI: 10.1016/S1005-8850(06)60084-4.

[6] Piccinia, J., Svobodaa, H. (2012). Effect of the plasma arc welding procedure on mechanical properties of DP700 steel. 11th International Congress on Metallurgy \& Materials SAM/CONAME, Procedia Materials Science, p.50 - 57 .

[7] Wu, D., Zhuang, L., Hui-sheng, L. (2008). Effect of controlled cooling after hot rolling on mechanical properties of hot rolled TRIP steel. Journal of Iron and Steel Research International, 15 (2):65-70, DOl: 10.1016/S1006-706 X (08)60034-5.

[8] Schmitt, JH., lung, T. (2020). New developments of advanced high-strength steels for automotive applications. Comptes Rendus Physique 19 (8): 641-656, DOI: 10.1016/j.crhy.2018.11.004.

[9] Nayaka, S.S., Baltazar Hernandeza, V.H., Okitaa, Y., Zhou, Y. (2012). Microstructure-hardness relationship in the fusion zone of TRIP steel welds. Materials Science and Engineering A, 551:73- 81, DOI: 10.1016/j.msea.2012.04.096.
[10] Ding, H., Song, D., Tang, Z., Yang, P. (2011). Strain hardening behavior of a TRIP/TWIP steel with $18.8 \%$ Mn. Material Science and Engineering A, 528(3): 868-873, DOl: 10.1016/j.msea.2010.10.040

[11] Pal, T.K., Chattopadhyay, K. (2010). Resistance spot weldability and high cycle fatigue behavior of martensitic (M190) steel sheet. Fatigue and Fracture of Engineering Materials and Structures, 34(1):4652, DOI: 10.1111/j.1460-2695.2010.01489.x

[12] De Cooman, B.C. (2004). Structure-properties relationship in TRIP steels containing carbide-free bainite. Current Opinion in Solid State and Materials Science, 8(4):285-303, DOI: 10.1016/j.cossms.2004.10.002.

[13] Kuziak, R., Kawalla, R., Waengler, S. (2008). Advanced high strength steels for automotive industry. Archives of Civil and Mechanical Engineering, 8(2): 103-117. DOl:10.1016/s1644-9665(12)60197-6

[14] Hilditch, T.B., De Souza, T., Hodgson, P.D. (2015). Properties and automotive applications of advanced high-strength steels (AHSS). Welding and Joining of Advanced High Strength Steels (AHSS), 9-28. DOI:10.1016/b978-0-85709-436-0.00002-3.

[15] Kučerová, L., Bystrianský, M. (2017). Comparison of thermo-mechanical treatment of C-Mn-Si-Nb and C-Mn-Si-Al-Nb TRIP steels. Procedia Engineering, 207:1856-1861, DOI: 10.1016/j.proeng.2017.10.951.

[16] Huang, J.Y., Zhu, Y.T., Liao, X.Z., Beyerlein, I.J., Bourke, M.A., Mitchell, T.E. (2003). Microstructure of cryogenic treated M2 tool steel. Materials Science and Engineering A, 339(1): 241-244, DOI:10.1016/ S0921-5093(02)00165-X.

[17] Meng, F.., Tagashira K., Azuma R., Sohma H. (1994). Role of etacarbide precipitations in the wear resistance improvements, ISIJ International 34, 205.

[18] Y. Dong, X.P. Lin, H.S. Xiao (1998). Deep cryogenic treatment of high speed steel and its. Mechanism, Heat Treatment of Metals 3, 55-59.

[19] Powell, G.W., Marshall, E.R., Backofen, W.A. (1958) Strain hardening of austenitic stainless steel. ASM Transactions Quarterly, 50:478497.

[20] Hecker, S.S., Stout, M.G., Staudhammer, K.P., Smith, J.L. (1982). Magnetic measurements and mechanical behavior. Metallurgical and Materials Transactions A 13(4): 619-626, DOI: 10.1007\%2FBF02644427.

[21] Yoo, S.W., Lee, C.S., Park, W.S., Kim, M.H., Lee, J.M. (2011). Temperature and strain rate dependent constitutive model of TRIP steels for low-temperature applications. Computational Materials Science, 50(7):2014-2027, DOI: 10.1016/j.commatsci.2011.02.002.

[22] Wang, W., Liu, B., Kodur, V. (2013). Effect of temperature on strength and elastic modulus of high-strength steel. J. Mater. Civ. Eng. 25:174182, DOI: 10.1061/(ASCE)MT.1943-5533.0000600

[23] Wang, X.D., Huang, B.X., Rong, Y.H., Wang L. (2006). Microstructures and stability of retained austenite in TRIP steels. Materials Science and Engineering A, 438-440:300-305, DOI: 10.1016/j. msea.2006.02.149.

[24] Kulin, S.A., Cohen, M., Averbach, B.L (1952). Effect of Applied stress on the martensitic transformation, Trans. AIME, 4:661-668, DOI:10.1007/BF03397742.

[25] Nageswararao, P., Kaurwar, A., Singh, D., Jayaganthan, R., (2014). Enhancement in strength and ductility of Al-Mg-Si alloy by cryo-rolling followed by warm rolling. Procedia Engineering, 75:123-128, DOI: 10.1016/j.proeng.2013.11 